\title{
EXPERIÊNCIAS DO ATENDIMENTO DOMICILIAR PARA A FORMAÇÃO PROFISSIONAL: UM RELATO DE EXPERIÊNCIA
}

\section{Barbara Leite da Silva Cruz'; Gabriele dos Santos Ibarro²; Lázaro Alberto Altermann $^{3}$; Natália Dal Forno ${ }^{4}$; Daniela Sanchotene Vaucher ${ }^{5}$; Morgana Christmann ${ }^{6}$; Alecsandra Pinheiro Vendrusculo ${ }^{7}$}

\section{RESUMO}

Introdução: O fisioterapeuta é parte essencial na promoção, prevenção e proteção dos indivíduos. Como forma de garantir a diversidade de práticas nos níveis de atenção à saúde, é importante que estudantes realizem ações interdisciplinares na atenção básica para aperfeiçoar a sua formação profissional. Objetivo: Relatar as experiências vivenciadas por estagiários de fisioterapia durante os atendimentos em domicílio para o processo de formação profissional. Método: Relato de experiência desenvolvido por estagiários do $9^{\circ}$ semestre do curso de fisioterapia no período de agosto a setembro de 2021 em uma Estratégia de Saúde da Família da região central do Rio Grande do Sul. Conclusão: É importante que ocorra o processo do acolhimento, humanização e escuta qualificada entre usuário e profissional. As visitas domiciliares proporcionam aos estudantes uma ampliação de seus conhecimentos, visto que a formação profissional deve estar em constante aprendizado, pois é desta maneira conhecimentos inovadores surgem e as experiências se consolidam.

Palavras-chave: Aprendizado; Atenção Básica; Fisioterapia.

Eixo Temático: Atenção Integral e promoção à Saúde (AIPS).

\section{INTRODUÇÃO}

O ambiente domiciliar é um local onde há a construção e fortalecimento do cuidado, visto que as crenças, costumes e valores pessoais de cada paciente são parte importante no planejamento das ações a serem realizadas pelos profissionais

\footnotetext{
${ }^{1}$ Barbara Leite da Silva Cruz - Universidade Franciscana barbara.cruz@ufn.edu.br.

${ }^{2}$ Gabriele dos Santos Ibarro - Universidade Franciscana Gabriele.ibarro@ufn.edu.br

${ }^{3}$ Lázaro Alberto Altermann - Universidade Franciscana altermannlazaro@gmail.com

${ }^{4}$ Natália Dal Forno - Universidade Franciscana natalia.dforno@ufn.edu.br

${ }^{5}$ Daniela Sanchotene Vaucher - Universidade Franciscana danivaucher@ufn.edu.br

${ }^{6}$ Morgana Christmann - Universidade Franciscana morgana.christmann@ufn.edu.br

${ }^{7}$ Alecsandra Pinheiro Vendrusculo - Universidade Franciscana alec@ufn.edu.br
} 
da saúde (LACERDA, 2015). De acordo com Borges (2018) o atendimento domiciliar é caracterizado como ações preventivas e assistenciais realizadas por uma equipe multiprofissional, onde são realizadas através de um conjunto de ações ambulatoriais organizadas de maneira planejada e contínua. Como forma de diminuir a fragmentação do foco à saúde, a atenção domiciliar auxilia na contribuição do acesso mais ampliado, acolhimento, igualdade, humanização e atenção integral à população (DIAS et al., 2015).

O profissional fisioterapeuta é um elemento essencial na prática de ações voltadas a todos os ciclos da vida, estas realizadas em conjunto com a equipe a quem faz parte, através do planejamento, controle, cumprimento e efetivação de políticas públicas (ALVES et al., 2020). É de grande importância que o fisioterapeuta esteja incluído na atenção básica participando dasações voltadas à saúde pública durante o processo de promoção, prevenção e proteção do bem estar dos indivíduos (MAIA et al., 2015).

Como parte do processo de formação de fisioterapeutas constam como itens essenciais a atenção voltada para a saúde, escolha do tratamento adequado através da prática baseada em evidência com respaldo científico, habilidades em comunicação, gerenciamento, administração, liderança e constante aprendizado e atualização profissional (BORGES, 2018).

Sabe-se que o processo de aprendizagem não é algo que se trabalha de maneira isolada, pois através associação de novas informações e o que já se possui de conhecimento, o aprendizado é baseado no ganho de conhecimentos e habilidades adquiridas por meio das experiências vividas (MEDEIROS; PIVETTA e MAYER, 2012).

Desde o início da formação do aluno na graduação, é importante que ações voltadas à atenção básica sejam incentivadas como forma de proporcionar aos estudantes a construção do conhecimento por meio de ações interdisciplinares com o objetivo de garantir a diversidade de práticas nos níveis de assistência a saúde (GAUER et al., 2017; MASSOTE; BELISÁRIO e GONTIJO, 2011). 
Sendo assim, o objetivo deste artigo é relatar as experiências vivenciadas por alunos de fisioterapia durante os atendimentos realizados em domicílio para 0 processo de formação profissional.

\section{METODOLOGIA}

O presente trabalho trata-se de um relato de experiência descrito por estagiários do $9^{\circ}$ semestre do curso de fisioterapia, denominados como Estagiário 1 , Estagiário 2, Estgiário 3 e Estagiário 4, no período em que foram realizados atendimentos domiciliares em uma Estratégia de Saúde da Família da região Central do Rio Grande do Sul, nos meses de agosto a setembro de 2021. Com base nas discussões e trocas de conhecimento entre os professores e estagiários, surgiu a ideia de relatar as experiências vivenciadas durante os atendimentos prestados na atenção básica e como esses fatores podem auxiliar no processo de formação profissional dos discentes.

\section{RESULTADOS}

\subsection{O PROCESSO DO ACOLHIMENTO COMO ESTRATÉGIA INICIAL DO ATENDIMENTO DOMICILIAR}

Como parte importante do serviço ofertado ao indivíduo que procura atendimento, seja ele público ou privado, percebemos como o acolhimento com os pacientes é um processo inerente e indispensável em qualquer prática relacionada ao cuidado em saúde.

O Ministério da Saúde (2010) descreve que o acolhimento é uma responsabilidade do profissional com o paciente desde a chegada até a saída, com base em uma escuta qualificada.

No estudo de Silva et al. (2019) é descrito que a universalidade ao acesso, presença de uma equipe multiprofissional e a humanização e cidadania voltadas para o cuidado, equipe de saúde, população e escuta são os três quesitos que definem o processo do acolhimento. Durante o processo de formação profissional de graduandos da área da saúde, estas são questões discutidas desde o primeiro 
semestre do curso, e nós como futuros profissionais devemos possuir esse olhar humanizado e capacidade de escuta qualificada no processo de acolher o paciente que chega ao serviço de saúde.

"Durante as práticas realizadas desde a graduação, sempre nos foi orientado que devemos escutar mais o paciente e o que ele nos relata desde o primeiro contato com o profissional no serviço de saúde. Isso já é considerada uma parte integrante do processo de acolhimento, dando a necessária atenção e cuidado humanizado a este paciente". (Estagiário 2 do Curso de Fisioterapia).

Desta maneira, é imprescindível que o acolhimento esteja presente para a efetivação da humanização na atenção básica na presença direta do diálogo entre paciente e profissional, como maneira de garantir ao usuário a sua valorização, proteção e acolhimento (RAMOS et al., 2018).

\subsection{EXPERIÊNCIAS ADQUIRIDAS NA ATENÇÃO BÁSICA}

Durante o período em que realizamos atendimentos domiciliares na Atenção Básica, algumas experiências e vivências agregaram ainda mais na nossa formação profissional. Corroborando com essa temática, Ferreira et al. (2015) relata que a construção da formação profissional é construída a partir do momento em que o estudante é inserido em um local em que haja representação de sujeitos, como forma de enriquecer o processo de construção do serviço.

Das vivências ocorridas que nos proporcionaram o ganho de experiências durante as práticas realizadas na Atenção Básica podemos destacar:

- Elaboração um plano de tratamento adequado com itens dispostos na casa do paciente.

- Aproximação dos estagiários com a equipe de saúde, como forma de conhecer e entender o contexto dos pacientes.

- Aproximação dos estagiários com a realidade que os pacientes se encontravam.

- Associação entre a teoria e o conhecimento prático adquirido com o passar dos atendimentos. 
- Possibilidade do estagiário em conhecer e realizar práticas no nível primário à saúde.

- Educar em saúde no sentido de fornecer a população uma melhor adesão ao tratamento.

\subsection{COMO ESSAS EXPERIÊNCIAS VIVENCIADAS AGREGARAM NA NOSSA FORMAÇÃO PROFISSIONAL}

Dos conhecimentos adquiridos, podemos relatar que todos foram cruciais nesse processo de formação profissional que estamos construindo.

Segundo o estudo de Medeiros et al. (2012) destacou-se que a presença do fisioterapeuta no domicílio permite que a intervenção realizada seja mais eficaz e específica, promovendo uma aproximação mais sólida do cotidiano familiar, além de permitir que ocorra uma aproximação com o contexto onde as pessoas estão inseridas, o que torna a visão da realidade mais fidedigna.

"Desde o início da faculdade e antes mesmo disto, foi nos ensinado a respeitar e não fazer diferenciação de classe. Mesmo tendo pacientes com realidades diferentes da minha, acredito ser um ponto positivo as visitas domiciliares para ambos os lados, pois é bom para eles que estão recebendo uma atenção fisioterapêutica, quanto é bom para nós para aprimorarmos o aprendizado, a própria humanização. A experiência de vida que eles passam para a gente é de suma importância para que sejamos profissionais qualificados" (Estagiário 1 do Curso de Fisioterapia).

Medeiros et al. (2012) ainda relata que a partir disso é possível observar que o ser humano não é algo fragmentado ou reduzido a parte biológica, mas que múltiplas dimensões fazem parte dele, visto que tal conduta ocorre nos níveis mais especializados de atenção.

Em relação ao contexto em que o atendimento fisioterapêutico domiciliar é realizado, diversas vezes foi necessário que tivéssemos a criatividadede elaborar uma intervenção com base nos objetos dispostos na casa do paciente.

"Embora alguns pacientes tenham condições de comprar equipamentos adequados, alguns precisam usar o que há em casa, e nem por isso o tratamento vai ser desqualificado. Sabemos que cada indivíduo possui uma 


\section{QPUFN}

realidade diferente da outra. Tendo em vista isso, é de grande relevância que o fisioterapeuta domiciliar tenha uma boa criatividade para usar objetos que o paciente possui em sua residência e transformar em equipamentos para realizar uma conduta com excelência, e isso parte do princípio onde o profissional precisa realizar um plano de tratamento adequado com as condições do indivíduo. (Estagiário 4 do Curso de Fisioterapia).

Já foi relatado que o acolhimento com o paciente é uma parte importante do processo de formação profissional dos alunos que vivenciam essas práticas domiciliares.

"VD é o melhor local para se construir vínculo e acolhimento. É uma grande experiência de aprendizagem conhecer pessoas diferentes com realidades opostas das nossas, muitas vezes pensamos que por sermos estudantes sabemos mais que os pacientes, mas isso não é verdade, na maioria dos casos os pacientes que nos ensinam, ensinam sobre a vida, sobre o afeto, carinho, responsabilidades e disciplina; e sobre isso não tem faculdade que ensine. É gratificante ver o resultado obtido com a fisioterapia nesses pacientes e é mais gratificante ter o reconhecimento deles" (Estagiário 3 do Curso de Fisioterapia).

Neste sentido, como forma de possibilitar o cuidado mais humanizado, acesso ampliado aos serviços de saúde, efetivo vínculo entre profissionais e usuários, além da resolução dos problemas e serviços realizados de maneira efetiva, o acolhimento é substancial nessas relações de cuidado entre os trabalhadores e demais indivíduos (LOPES et al., 2015).

\section{DISCUSSÃO}

O fisioterapeuta está alcançando cada vez mais espaço na saúde coletiva e nos serviços de atenção primária como nas Estratégias de Saúde da Família. Esta introdução é um processo ainda em construção, com o objetivo de otimizar o trabalho da fisioterapia, alcançando grupos de pessoas e influenciando de forma positiva na qualidade de vida da sociedade (RAGASSON et al., 2006; MACIEL et al., 2005). 
O artigo de Bispo Júnior (2010), enfatiza o dever dos profissionais da saúde na atuação para a prevenção de doenças e hábitos ruins que possam prejudicar a saúde, ao passo que, existe um extenso campo deatuação em saúde pública para promover à saúde e melhorar a qualidade de vida, inibindo osurgimento de doenças que podem ser detidas. Na vivência da atenção básica, pode-se realizar o planejamento dos atendimentos utilizando instrumentos dispostos na casa do paciente, aproximando o tratamento da realidade de cada indivíduo.

Bispo Júnior (2010) ainda ressalta de maneira importante que essa população pode estar correndo risco devido a diversos fatores como os de natureza educacional, social, econômica, biológica, dentre outros, sendo assim para identificar esses riscos, o fisioterapeuta deve atuar juntamente com uma equipe multidisciplinar e utilizar os conhecimentos de outras áreas, como a epidemiologia, a geografia e as ciências sociais. A atenção primária, frisa a análise do indivíduo de maneira integral, no entanto, ainda existe a supremacia das classes, dificultando a troca entre os profissionais da equipe.

Para Santos, et.al. (2014) a publicação das Diretrizes Curriculares Nacionais (DCN) foi uma ação importante para a mudança na formação dos cursos da saúde. As DCN do curso de Fisioterapia dispõem uma formação generalista, humanística, crítica e reflexiva, qualificando oegresso para atuar no Sistema Único de Saúde - o SUS - assim como em todos os níveis de atenção.Também apresentam a proposta da formação orientada por competências ehabilidades.

O conceito de competência implica na mobilização de conhecimentos, habilidades e atitudes, com uma abordagem dialógica em que se articulam tarefas e recursos cognitivos, afetivos, atitudinais e psicomotores, aproximando os estagiários com a realidade que os pacientes se encontram, no mesmo sentido que é possível a associação entre a teoria e o conhecimento prático adquirido com o passar dos atendimentos (BRAGHINI; FERRETTI; FERRAZ, 2016).

\section{CONCLUSÃO:}

Mediante as experiências descritas nesse relato, acreditamos que é de grande importância criar um vínculo com o paciente para ele ter uma correta adesão 
ao tratamento, além de possuir um olhar humanizado com o adequado acolhimento ao indivíduo.

Cabe a nós futuros profissionais, aliar o contexto que o paciente está inserido com as práticas fisioterapêuticas, visto que em diversos momentos foi necessária a criatividade em elaborar uma conduta com base nos recursos dispostos no domicílio do paciente. Através disso, podemos concluir que isto foi importante para nossa experiência profissional em relação à adaptação de técnicas diante do cenário domiciliar.

Tendo em vista as considerações citadas acima, é de suma importância vivenciar essas diversas visitas domiciliares para ampliar os nossos conhecimentos e visões desenvolvidas sobre os diferentes serviços de saúde, garantindo a capacidade do profissional em realizar uma escuta qualificada com o usuário que busca o serviço de saúde na atenção básica.

Concluímos que a formação profissional de estagiários da área da saúde é um processo contínuo e que deve estar em constante aprendizado. 


\section{REFERÊNCIAS BILBIOGRÁFICAS:}

ALVES, Nágila Silva et al. Perspectivas sobre o trabalho do fisioterapeuta na atenção básica: uma revisão integrativa. Revista CPAQV-Centro de Pesquisas Avançadas em Qualidade de Vida, v. 12, n. 1, p. 2, 2020.

BISPO JÚNIOR, José Patricio. Fisioterapia e saúde coletiva: desafios e novas responsabilidadesprofissionais. Ciência \& Saúde Coletiva, v. 15, n. 1, p. 16271636, 2010.

BORGES, Kamylla Pereira. Competências para formação do fisioterapeuta no âmbito das diretrizes curriculares e promoção da saúde. Saúde e Pesquisa, v. 11, n. 2, p. 347-358, 2018.

BORGES, P. C. S. Atendimento domiciliar: uma experiência interdisciplinar. 21 ed. Palhoça: Editora Unisul, 2018.

BRAGHINI, Cássia Cristina; FERRETTI, Fátima; FERRAZ, Lucimare. Physiotherapist's role in the NASF: perception of coordinators and staff. Fisioterapia em Movimento, Curitiba, v. 29, n. 4, p. 767- 776, Dez. 2016.

Brasil. Ministério da Saúde. Secretaria de Atenção à Saúde. Núcleo Técnico da Política Nacional de Humanização. HumanizaSUS: Documento base para gestores e trabalhadores do SUS / Ministério da Saúde, Secretaria de Atenção à Saúde, Núcleo Técnico da Política Nacional de Humanização. - 4. ed. 4. reimp. - Brasília : Editora do Ministério da Saúde, 2010.

MAIA, Francisco Eudison da Silva et al. A importância da inclusão do profissional fisioterapeuta na atenção básica de Saúde. Revista da Faculdade de Ciências Médicas de Sorocaba, v. 17, n. 3, p. 110-115, 2015.

DIAS, Mariana Borges et al. A Política Nacional de Atenção Domiciliar no Brasil: potencialidades, desafios e a valorização necessária da atenção primária à saúde. Journalof Management \& Primary Health Care, Brasil, v. 6, n. 1, p. 1-7, 2015.

GAUER, Ana Paula Maihack et al. Ações de reorientação da formação profissional em Fisioterapia: enfoque sobre cenários de prática. Interface-Comunicação, Saúde, Educação, v. 22, p. 565-576, 2017.

LACERDA, Maria Ribeiro. Brevidades sobre o cuidado domiciliar. Revista de Enfermagem da UFSM, v. 5, n. 2, 2015. 
LOPES, Adriana Santos et al. O acolhimento na Atenção Básica em saúde: relações de reciprocidade entre trabalhadores e usuários. Saúde em debate, v. 39, p. 114123,2015

MACIEL, R.V.; SILVA, P.T.G.; SAMPAIO, R.F.; DRUMMOND, A.F. Teoria, prática erealidade social: uma perspectiva integrada para o ensino de Fisioterapia. Fisioterapia em Movimento. Curitiba, v. 18, n. 1, p. 11-17, 2005.

MASSOTE, Alice Werneck, BELISÁRIO, Soraya Almeida, GONTIJO, Eliane Dias. Atenção primária como cenário de prática na percepção de estudantes de medicina. Revista Brasileira de Educação Médica, v.35, n.4, p. 445-53, 2011.

MEDEIROS, Paulo Adão de; PIVETTA, Hedioneia Maria Foletto; MAYER, Margarida da Silva. Contribuições da visita domiciliar na formação em fisioterapia. Trabalho, educação e saúde, v. 10, p. 407-426, 2012.

RAGASSON, Carla Adriane Pires et al. Atribuições do fisioterapeuta no programa de saúde da família: reflexões a partir da prática profissional. Revista Olho Mágico, v. 13, n. 2, p. 1-8, 2006.

RAMOS, Elen Amaral et al. Humanização na Atenção Primária à Saúde. Revista Médica de Minas Gerais, n. 5, vol. 28, p. 176-180, 2018.

SANTOS, Mara Lisiane de Moraes dos. Competências eatribuições do fisioterapeuta na Atenção Primária à Saúde. Fisioterapia Brasil, v. 15, n. 1, p. 69-76, 2014.

SILVA, Larissa Ádna Neves et al. Acesso e acolhimento na Atenção Básica da região Oeste do Pará. Saúde em Debate, v. 43, p. 742-754, 2019. 